\title{
REVIEW
}

This is an open access article distributed under the terms of the Creative Commons BY-NC-ND Licence

\section{Fluorine: a biohazardous agent for plants and phytoremediation strategies for its removal from the environment}

\author{
A. BANERJEE and A. ROYCHOUDHURY* \\ Post Graduate Department of Biotechnology, St. Xavier’s College, Kolkata - 700016, West Bengal, India
}

\begin{abstract}
Fluorine, one of the most abundant elements found on earth, acts as an environmental xenobiotics even at sparingly low concentrations. Uncontrolled anthropogenic activities have steeply increased the F content in the air, water, and soil. Irrigation of crops and vegetables with $\mathrm{F}$ contaminated groundwater or agricultural practices in contaminated soils adversely affect their physiological and biochemical parameters, leading to inhibited growth and productivity. Some plants can translocate the toxic ions from roots to shoots and accumulate them in the edible parts. Bioaccumulations of $\mathrm{F}$ have hazardous outcomes, as their concentrations in edible parts can be higher than the safe value. Screening of F hyperaccumulators and F-tolerant plants has been performed to facilitate phytoremediation. Some plant bioindicators have been identified which can be used to analyse the extent of atmospheric F pollution. Cumulative use of these organisms through proper scientific planning programs can potentially improve the agricultural soil quality in terms of their toxic F content. Future research should focus on proper execution of these phytoremediative strategies via robust field trials. High throughput genetic analyses should also be performed to identify quantitative trait loci which can be exploited to generate F-tolerant characters in susceptible crop cultivars.
\end{abstract}

Additional key words: chlorophyll, F bioindicators, F hyperaccumulators, growth, photosynthesis, xenobiotics.

\section{Introduction}

The earth's crust contains about $950 \mathrm{mg}(\mathrm{F}) \mathrm{kg}^{-1}$ (soil). It is the $13^{\text {th }}$ most abundant element in nature and is stored as Fs in naturally occurring minerals like fluorspar, cryolite, fluorapatite, etc. The extremely high electronegativity accounts for the high $\mathrm{F}$ reactivity (Hong et al. 2016). Low doses of $\mathrm{NaF}$ ranging between $0.3-1.0 \mathrm{mg} \mathrm{dm}^{-3}$ are often introduced in drinking water by the municipalities to prevent dental caries and osteoporosis. However, ingestion of $\mathrm{F}$ beyond the safe limit of $1.5 \mathrm{mg} \mathrm{dm}^{-3}$ (proposed by the World Health Organization, WHO) results in irreversible damage, e.g., skeletal deformities, non-skeletal fluorosis, and secondary neurological complications in animals as well as in humans (Choubisa 2013).

F contamination exerts hazardous effects on the ecosystem. Plants can either take up F from the contami- nated soil via roots or can absorb $\mathrm{F}$ from the atmosphere (Bhat et al. 2015). F released into the atmosphere from anthropogenic sources; it hydrolyzes into corrosive hydrogen $\mathrm{F}$ (HF), which reacts with materials in aerosols and vapour to form non-volatile stable Fs (Hong et al. 2016). High content of atmospheric F, reaching a maximum value of $2 \mathrm{mg} \mathrm{kg}$ (total air) was reported during atmospheric precipitation in Poland (Walna et al. 2013). It has been seen that HF content as low as $1 \mu \mathrm{g} \mathrm{kg}-$ ${ }^{1}$ (total air) can initiate injuries in the sensitive plants (Gupta et al. 2009). A massive F deposition of $52 \mathrm{mg} \mathrm{m}^{-}$ (soil) year-1 was detected during a two-year study in Poland (Walna et al. 2013).

Even exposure to low amounts of $\mathrm{F}$ is sufficient to cause physiological complications like necrotic lesions, burning, chlorosis, leaf damage, and inhibition in

Submitted 13 April 2018, last revision 27 August 2018, accepted 3 September 2018.

Abbreviations: AsA - ascorbic acid; Car - carotenoids; CAT - catalase, CDPK - calcium dependent protein kinase; Chl - chlorophyll; GPX - glutathione peroxidase; POX - peroxidase; Pro - proline; SOD - superoxide dismutase.

Acknowledgements: Financial assistance from the Council of Scientific and Industrial Research (CSIR), Government of India [grant 38(1387)/14/EMR-II] and from the Science and Engineering Research Board, Government of India [grant EMR/2016/004799] to A. Roychoudhury is gratefully acknowledged. The University Grants Commission, Government of India is acknowledged for providing the Junior Research Fellowship to A. Banerjee.

* Corresponding author; e-mail: aryadeep.rc@gmail.com 
development and reproductive capability in the sensitive plants. The stress-associated symptoms in plants are observed gradually and more prominently on prolonged exposure to F (Hong et al. 2016). F bioaccumulation in the edible plant parts (Mondal and Gupta 2015) is a problem of global interest because different countries across Asia, Africa, Australia, and South America are facing acute endemic fluorosis (Susheela 1999, Meenakshi and Maheshwari 2006).

\section{F translocation from soil to plants}

Physico-chemical properties of fluorides in the soil: According to Susheela (1999), F content in water have been recorded as high as $48 \mathrm{mg} \mathrm{dm}^{-3}$ across different states of India. High F content has been detected in rivers (12 - $\left.26 \mathrm{mg} \mathrm{dm}^{-3}\right)$, springs $\left(15-63 \mathrm{mg} \mathrm{dm}^{-3}\right)$ and alkaline ponds and lakes $\left(60-690 \mathrm{mg} \mathrm{dm}^{-3}\right)$ in northern Tanzania (Nanyaro et al. 1984). Farooqi et al. (2007) reported that out of the 147 groundwater samples tested in Pakistan, $75 \%$ largely exceed the $\mathrm{F}$ safe limit $\left(1.5 \mathrm{mg} \mathrm{dm}^{-3}\right)$ and this concentration is toxic not only for animals and humans, but also affected plants. It has been seen that extremely contaminated (often heavy clay) soil can reach content of Fs $1000-3500 \mathrm{mg} \mathrm{kg}-1$ (d.m.) (Hong et al. 2016) but the normal soil $F$ content can range between 150 - $400 \mathrm{mg} \mathrm{kg}^{-1}$ (d.m.) (Bhat et al. 2015). However, the critical value of soil $F$ beyond which $F$ uptake by plants and translocation to shoots increased species-specific.

$\mathrm{F}$ is a ubiquitous toxin which mostly remains adsorbed to clays and oxy-hydroxides with a very low percentage dissolved in the soil solution (Marier 1971). Therefore, F mobility varies with the soil permeability and sorption capacity. The sorption capacity is dependent on soil $\mathrm{pH}$, types of sorbents and soil salinity (Tylenda 2011). Due to the formation of stable bonds with $\mathrm{Fe}^{2+/ 3+}$, $\mathrm{Al}^{3+}, \mathrm{Mg}^{2+}$ and $\mathrm{Ca}^{2+}, \mathrm{F}$ content is much higher in the silt, clay loam and non-calcareous (containing high $\mathrm{Al}^{3+}$ ) soil than in sandy soil (Hong et al. 2016). Soils with high $\mathrm{Ca}^{2+}$ content are effective in fixing $\mathrm{F}$ in the form $\mathrm{CaF}_{2}$ (Abugri 2010). As a result, a small percentage of $\mathrm{F}^{-}$exists in free form in soil containing high $\mathrm{Al}$ (Vasudevan et al. 2003). Thus, soil need to be alkaline in order to contain high doses of free $\mathrm{F}^{-}$. This aids in the release of $\mathrm{F}$ from the soil surface resulting in enhanced plant bioavailability. Again, alkaline $\mathrm{pH}$ reduces soil $\mathrm{F}$ retention. This is due to the formation of electrostatic potential and displacement of bound $\mathrm{F}^{-}$by $\mathrm{OH}^{-}$(Saxena and Rani 2012). Therefore, F bioavailability for plants is greatly dependent on the $\mathrm{pH}$ and physico-chemical properties of the soil. Formation of $\mathrm{AlF}_{\mathrm{x}}$ under acidic conditions increases water solubility of $F$, whereas alkaline conditions promote desorption of free $\mathrm{F}$ (Wehr et al. 2014) (Fig. 1).
Though a significant amount of research has been conducted on multiple abiotic stresses like salinity, drought, cold, heat, light and heavy metal toxicity (Banerjee and Roychoudhury 2017, 2018a), less literature is available on the effects of this 'slow poison' on plants. In this review, we have thoroughly discussed the adverse effects of $\mathrm{F}$ as a biohazardous agent as well as highlighted the prospects of $\mathrm{F}$ phytoremediation.

Fluoride entry into plants: Plants absorb $\mathrm{F}$ from air, water, and soils. However, the amount of $F$ uptake varies with the type of plant, soil characteristics, and the amount of $F$ in the air, soil, or water used for irrigation (Anshumali 2014). F content in the tissues of Triticum aestivum was analysed by a potentiometric method using a F-selective electrode. Different content of $F$ was observed in the stems, leaves, and roots (Agrawal and Chauhan 2014). Variable $F$ accumulation in the shoot biomass has been reported even among cultivars. This is because, in spite of passive uptake of $\mathrm{F}$ by roots, the variable root-shoot translocation efficiency plays a crucial role in determining $\mathrm{F}$ accumulation in shoots (Mondal 2017).

The $\mathrm{Ca}^{2+}$ content in the root cell wall primarily determine $\mathrm{F}$ sensitivity. This is because $\mathrm{F}^{-}$is scavenged by $\mathrm{Ca}^{2+}$ present in the root cell wall. Thus, species with high $\mathrm{Ca}^{2+}$ in this region better control the entry $\mathrm{F}^{-}$. It has been hypothesized that $\mathrm{F}^{-}$is absorbed through chloride channels and chloride deficiency enhances $\mathrm{F}^{-}$uptake (Baunthiyal and Ranghar 2013). Aquaporins might also be involved in $\mathrm{F}$ transport (Baunthiyal and Ranghar 2013). Due to the high electronegativity of $F$, it is quite obvious that symplastic transport is not permitted. The fixed negative charge of the plasma membrane excludes the permeability of $\mathrm{F}$ ions. Hence, apoplastic transport via the cell wall and intercellular spaces is common (Agrawal and Chauhan 2014) (Fig. 1). The endodermis acts as a protective barrier and prevents effective $\mathrm{F}$ transport to the vascular tissues, thereby minimizing the root-to-shoot translocation. This is in line with the observation of Jha et al. (2009) who showed that the order of F retention in Allium cepa is roots $>$ shoots $>$ bulbs. Thus, the $\mathrm{F}$ that reaches the shoots is transported through a non-selective route. This route might bypass the endodermis via an unknown mechanism (Hong et al. 2016). The xylem sap flow carries $F$ to the leaves (Panda 2015). The F accumulation in the shoots varies across species and is a function of $\mathrm{F}$ concentration in the rooting medium and the rate of water flow (Pitman 1985). In a recent research, Chen et al. (2017) found synergistic negative effect of $\mathrm{F}$ and $\mathrm{Cd}$ on the growth of radish plants. Both $\mathrm{F}$ and $\mathrm{Cd}$ accumulation could be detected within the leaves and at the leaf tips (Chen et al. 2017). 


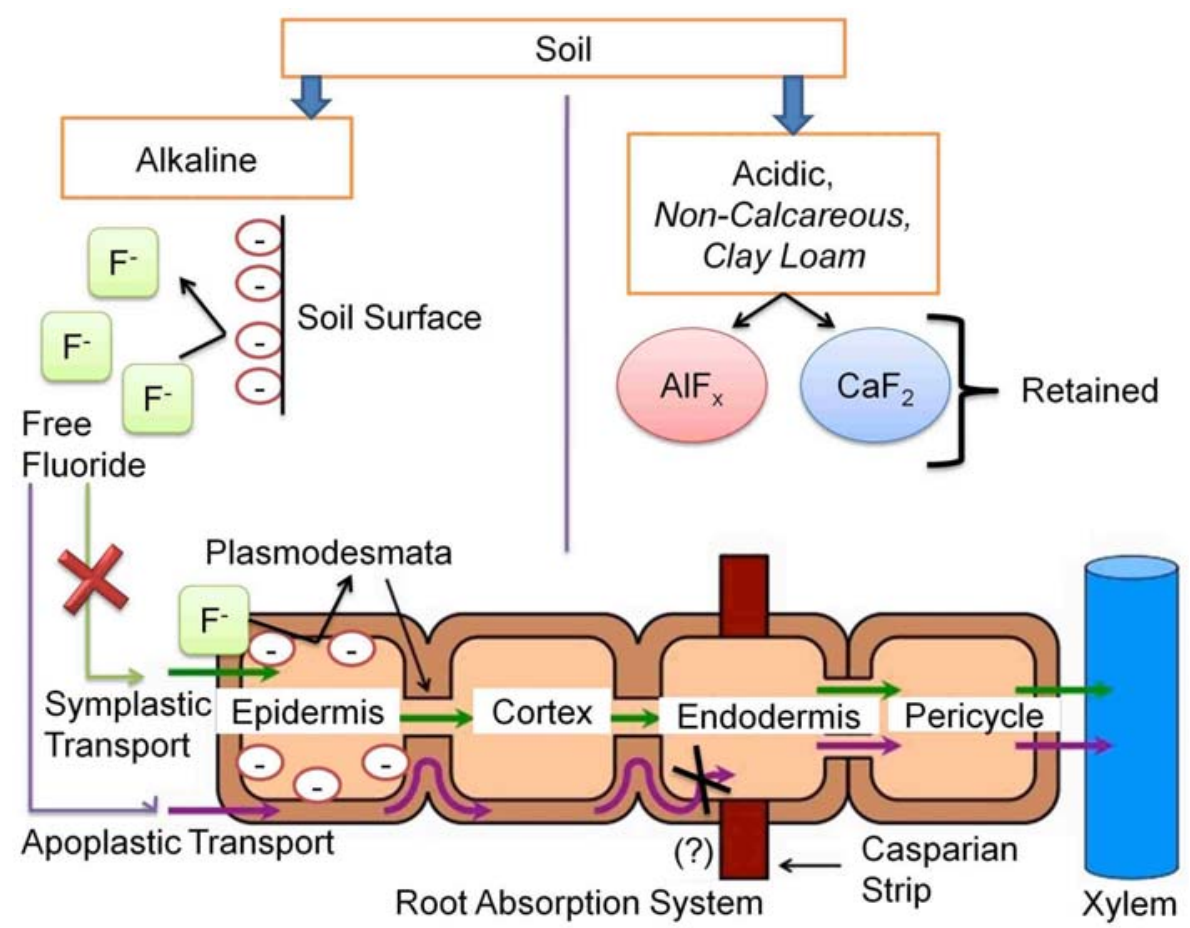

Fig. 1. $\mathrm{F}$ is retained as aluminium $\mathrm{F}$ complexes $\left(\mathrm{AlF}_{\mathrm{x}}\right)$ and calcium $\mathrm{F}\left(\mathrm{CaF}_{2}\right)$ in non-calcareous, clay loam soils at acidic $\mathrm{pH}$ and is unavailable to the plant roots. Under alkaline conditions, the bioavailability of free $F$ increases due to repulsion of negatively charged $\mathrm{F}$ ions with the negative soil surfaces. The free $\mathrm{F}$ is absorbed via chloride transporters or aquaporins in the plant roots and it is transported through the apoplastic route. Due to strong repulsions between $\mathrm{F}$ and the negatively charged plasma membrane, transport via the symplastic route is less common. The endodermis acts as a barrier and prevents $\mathrm{F}$ ions to progress towards the pericycle. $\mathrm{F}$ transport towards the vascular tissues from this point is not well characterized (?) and possibly occurs through a non-selective route bypassing the endodermis.

\section{Fluoride phytotoxicity}

Morphological and anatomical symptoms: A cell suspension of Arabidopsis thaliana treated with $20 \mathrm{mM}$ $\mathrm{NaF}$ for $2 \mathrm{~h}$ exhibited no loss of cell viability. However, cellular development was strictly inhibited by exposure to even $1 \mathrm{mM} \mathrm{NaF}$ for $10 \mathrm{~d}$ (Pulyaevskaya et al. 2011). Fs can accumulate in the plant foliage and typical injury is marginal and tip necrosis gradually spread inward. $F$ is carried and deposited in the leaf edges by the vascular tissues (Fig. 2). Depending on the content in the cell sap, F firstly damages the spongy mesophyll and lower epidermis and then chloroplasts in the palisade cells and the upper epidermis (Panda 2015). Members of Pinaceae exhibit necrotic patches which spread from the needle tip to the base (Hong et al. 2016). More detail information concerning F-induced damages in different plant species are in Table 1 Suppl.

F stress and initial development in plants: Proper seed germination and seedling growth are crucial for plant survival. F interferes with active metabolism and lowers the rate of cell division and expansion. This inhibits germination and early seedling development (Ram et al. 2014). Seed germination is also affected due to F-induced degeneration of gibberellic acid (GA) in the aleurone, leading to the abnormal metabolism of endosperm saccharides (Gadi et al. 2016). Inappropriate seedling development and unbalanced nutrient uptake due to $\mathrm{F}$ interference reduced shoot and root length, fresh and dry masses and vigour index in Oryza sativa, Triticum aestivum, Cyamopsis tetragonoloba, Cicer arietinum, Citrullus lanatus, and Abelmoschus esculentus (Gupta et al. 2009, Datta et al. 2012, Ram et al. 2014, Gadi et al. 2016, Iram and Khan 2016).

Impact of fkuorides on photosynthesis: $\mathrm{The}^{2+} \mathrm{Ca}^{2+}$ is a crucial secondary messenger which participates in multiple signalling cascades in the plant system (Roychoudhury and Banerjee 2017). F chemically interacts with $\mathrm{Ca}^{2+}$ and precipitates as $\mathrm{CaF}_{2}$ to alter membrane permeability (Stevens et al. 1998). Calcium dependent protein kinases (CDPKs) act as signalling hubs in multiple abiotic stress responses (Roychoudhury and Banerjee 2017). Lowering of intracellular $\mathrm{Ca}^{2+}$ content can thus disrupt the abiotic stress-responsive signalling process during $\mathrm{F}$ stress (Fig. 2).

Fs act as metabolic inhibitors in plants (Iram and Khan 2016). Prolonged $F$ stress induces chlorosis and deteriorates basic physiological processes like 
photosynthesis. F strongly associates with $\mathrm{Mg}^{2+}$ and $\mathrm{Fe}^{2+/ 3+}$ and decreases their upward translocation to the leaves (Elloumi et al. 2005). This inhibits the biosynthesis of chlorophylls (Chls) and carotenoids (Cars) (Table 1). The participation of $\gamma$-aminolevulinic acid in the Chl biosynthetic pathway is also prevented during $\mathrm{F}$ stress (Wallis et al. 1974). The $\mathrm{MgF}^{+}$complex can degrade plant pigments (Abdallah et al. 2006). Content of Chl $a$ and $b$ significantly decreased in Oryza sativa and Triticum aestivum exposed to F stress (Gupta et al. 2009, Bhargava and Bhardwaj 2010). Chakrabarti and Patra (2015) showed Chl and Car degradation in two indica rice cultivars exposed to 10,20 , and $30 \mathrm{mg} \mathrm{dm}^{-3}$ NaF. Similarly, Mondal (2017) detected pigment degradation in four indica rice cultivars exposed to 5,10 , and $20 \mathrm{mg} \mathrm{dm}^{-3} \mathrm{NaF}$. Severe chlorosis and necrosis were seen on the young leaves of Populus deltoides irrigated with water containing $500 \mathrm{mg} \mathrm{dm}^{-3}$ of F for $100 \mathrm{~d}$ (Singh and Verma 2013). Antho-cyanins have antioxidant properties and have been associated with stress tolerance (Paul et al. 2017). Salicornia brachiata plants exposed to $\mathrm{F}$ for $100 \mathrm{~d}$ exhibited high anthocyanin content and decrease in content of Chls and Cars (Reddy and Kaur 2008). Radish plants growing on soils co-contaminated with $\mathrm{F}$ and $\mathrm{Cd}$ exhibited high absorption of $\mathrm{Zn}^{2+}$ and $\mathrm{Mn}^{2+}$. However, $\mathrm{Cu}^{2+}$ absorption was drastically reduced
(Chen et al. 2017). Since these micronutrients often act as co-factors of essential enzymes, their altered profile influence important signalling pathways associated with the growth and development of the plant (Banerjee and Roychoudhury 2018b).

Severe chlorosis induced by $\mathrm{F}$ stress detrimentally affects photosynthesis (Mondal 2017, Banerjee and Roychoudhury 2018c). Activities of the enzymes associated with Calvin cycle are reduced. The main enzymes affected by $\mathrm{F}$ exposure are chloroplast ATPase, ribulose 1,5 bisphosphate carboxylase/oxygenase, and sucrose synthetase (Baunthiyal and Ranghara 2014). F-induced stress impaired the stomatal conductance resulting in limited $\mathrm{CO}_{2}$ diffusion from the atmosphere into the cell and reduced photosynthetic $\mathrm{CO}_{2}$ assimilation (Singh et al. 2013). Singh and Verma (2013) determined $\mathrm{Chl}$ fluorescence and showed reduced photosynthetic efficiency $\left(\mathrm{F}_{\mathrm{v}} / \mathrm{F}_{\mathrm{m}}\right)$ in poplar plants exposed to $\mathrm{F}$ stress. The chlorophyll fluorescence yield was monitored by plant efficiency analyzer. The decrease in photosysterm (PS) II occurs due to distinct decrease in the activity of chlorophyll binding proteins (CP43 and CP47) of core antenna subunits of PS II as affected by $\mathrm{F}$ treatment, along with increase in PS I. Effects of $F$ on photosynthesis are pronounced (Table 1 Suppl.), but the physiological basis of such deterioration is still required

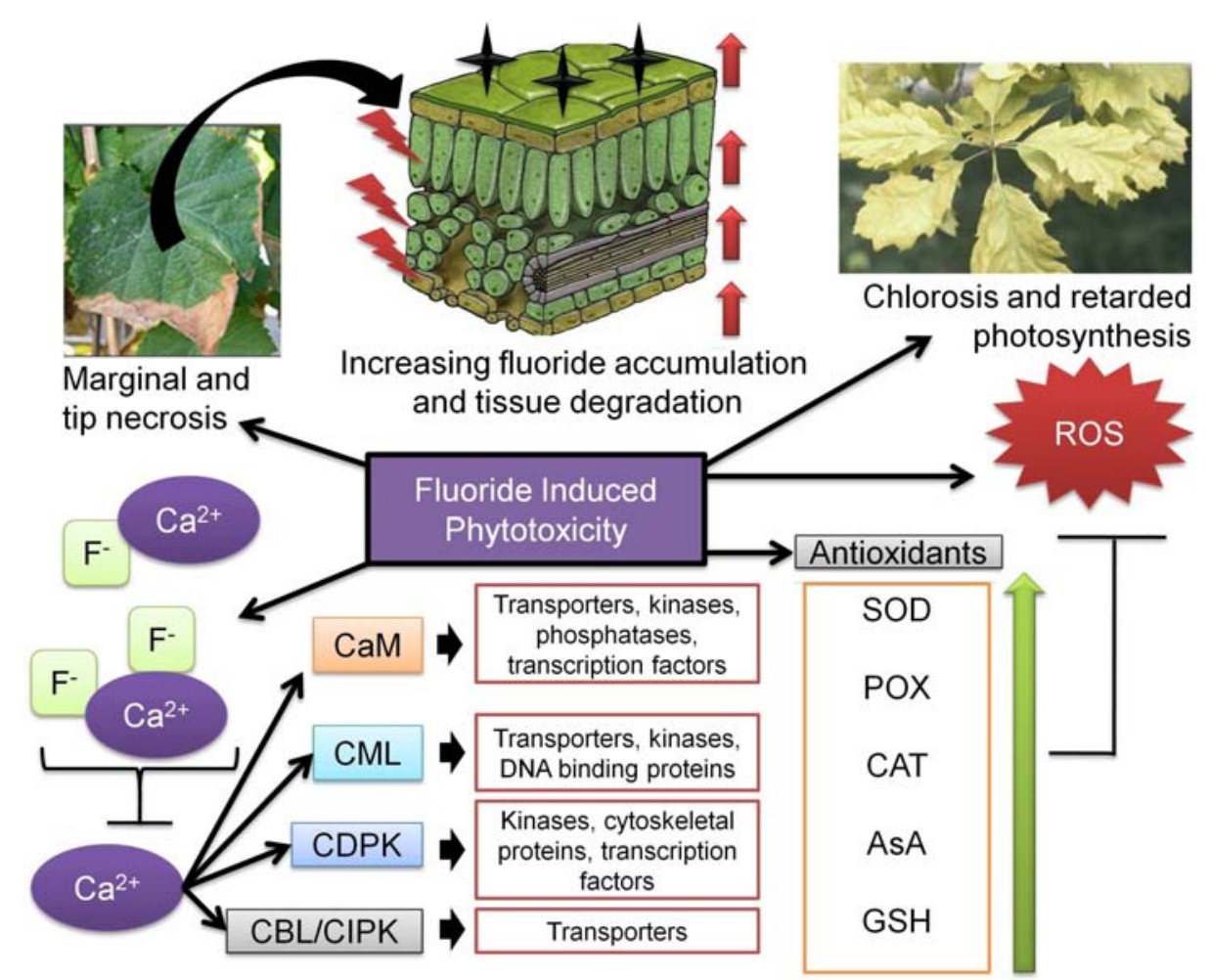

Fig. 2. Accumulation of $F$ triggers marginal and tip necrosis in leaves accompanied by degradation of mesophyll tissues. Gradual increase of $\mathrm{F}$ content firstly affects lower epidermis, then spongy mesophyll, palisade parenchyma, and finally the upper epidermis. The anatomical deterioration is also associated with physiological abnormalities like chlorosis and retarded photosynthesis. F also chelates calcium $\left(\mathrm{Ca}^{2+}\right)$ ions and hinders downstream signalling pathways. $\mathrm{Ca}^{2+}$ dependent molecular signaling components like calmodulin $(\mathrm{CaM})$, CaM-like proteins $(\mathrm{CML})$, calcium dependent protein kinase (CDPK), calcineurin B-like protein (CBL)/CBLinteracting protein kinase (CIPK), etc., are inactivated. $\mathrm{F}$ also induces oxidative damages by triggering the accumulation of ROS. This activates the antioxidant machinery to protect the plant. 
to be elucidated. One possibility of indirect effects is F- induced water stress as low relative water content (RWC) was observed in plants like O. sativa, T. aestivum, Brassica oleracea, B. juncea, Beta vulgaris, Apium graveolens, Daucus carota,Allium sativum, Pisum sativum, Cucumis sativa, and Lens culinaris irrigated with $\mathrm{F}$ contaminated water (Mondal and Gupta 2015) (Table 1 Suppl.). Such low RWC also inhibits normal growth.

Biochemical alterations induced by Fs: Biochemical parameters are important indices for determining plant sensitivity against a particular stress. F stress suppresses respiration up to $50 \%$ by inhibiting activities of mitochondrial and glycolytic enzymes like succinate dehydrogenase, malate dehydrogenase, and enolase (Miller 1993). F tends to accumulate in the cellular organelles with alkaline $\mathrm{pH}$ like mitochondria and chloroplasts and inhibit the acid phosphatase and membrane ATPase activities (Struglics et al. 2000). The $\mathrm{AlF}_{4}^{-}$complex is a phosphate ion analogue and so it can inhibit $\mathrm{P}$ transport. Such fluoride-mediated inhibition in $\mathrm{P}$ transport has been observed in the membrane proteins of potato tubers exposed to elevated content of F (Golicnik 2010, Struglics et al. 2000). Inhibition of phosphorylation directly prohibits processes like glycolysis, nucleotide synthesis, signalling, etc. (Barbier et al. 2010). Mondal (2017) reported significant lipid peroxidation and root ion leakage in four indica rice cultivars exposed to increasing concentrations of $\mathrm{F}$.

Amino acids and total nitrogen metabolism are also affected in plants exposed to F. An increase in free amino acid content due to degradation of the soluble proteins was observed in the leaves of tea plants exposed to $\mathrm{F}$ stress. The leaves accumulated high content of asparagine, aspartic acid, serine, glutamic acid, and pipecolic acid (Cai et al. 2016). An interesting correlation between nitrogen metabolism and $\mathrm{F}$ stress has been observed among $\mathrm{F}$ tolerant and hypersensitive plants (Szostek and Ciecko 2017). It was seen that plants with variable sensitivities to $F$ stress accumulated variable content of total $\mathrm{N}$ in the shoot biomass in a species-specific manner (Table 1 Suppl.). Zea mays, being $\mathrm{F}$ tolerant, possibly has developed an evolutionary strategy of preventing Finduced protein degradation and hence the stressed plant does not require up regulation of protein synthesis and low N content could be detected (Szostek and Ciecko 2017). On the contrary, in spite of being F tolerant, Lupinus luteus plants accumulated high amount of total $\mathrm{N}$ in their shoots (Szostek and Ciecko 2017). Thus, these plants exhibit $F$ tolerance by increasing protein synthesis and tilting the equilibrium away from protein degradation. $\mathrm{F}$ hypersensitive plants like Lupinus angustifolius has been found to record high $\mathrm{N}$ content in the shoots due to unregulated protein degradation (Table 1 Suppl.).
F stress deteriorates nitrogen assimilation by inhibiting nitrate reductase, the rate limiting enzyme of nitrogen acquisition (Rao et al. 2013). The F-induced decline in the total protein content can be explained by channelizing the degraded products towards metabolic processes for obtaining energy and tackling stress (Szostek and Ciecko 2017). Mulberry plants grown under $\mathrm{F}$ stress showed a $59 \%$ decrease in leaf protein content (Rao et al. 2013). Pal et al. (2012) reported decreases in total protein content in 13 plant species irrigated with $\mathrm{F}$ contaminated water. Abelmoschus esculentus seedlings irrigated in $\mathrm{F}$ contaminated water, exhibited reduced percentages of nitrogen and protein compared to the control plants (Iram and Khan 2016). However, potato plants grown in $\mathrm{F}$ contaminated soil exhibited an increase in total protein content possibly to counterbalance the protein loss (Saleem et al. 2015).

$F$ stress decreases the water potential by inhibiting water uptake and the water conductivity of the roots. As a result, the osmotic potential increases (Gadi et al. 2016). Under such conditions, plants tend to accumulate inorganic ions, soluble sugars, and compatible solutes (osmoprotectants) to maintain the cellular hydration (Paul et al. 2017). Increase in the content of compatible solutes like amino acids, proline (Pro), and phenols have been reported (Table 1 Suppl.). Compatible solutes also protect the membrane systems and stabilize protein and enzymatic structures. Pro has even been associated with post-stress recovery and the generation of stress memory via epigenetic regulations during salt stress (Roychoudhury et al. 2015). Remarkable accumulation of soluble sugars has been observed in several plant species exposed to F stress (Table 1 suppl.). They act as osmotica to facilitate root water transport and stabilize proteins and membrane structures (Ram et al. 2014, Banerjee and Roychoudhury 2016). Elloumi et al. (2005) observed steady accumulation of nonreducing sugars in plants grown under $\mathrm{F}$ stress.

F stress and the antioxidant system: The discussions in the previous sections altogether conclude that $\mathrm{F}$ severely retards the physiological parameters in sensitive plants. Such inhibitions might be due to unregulated production of reactive oxygen species (ROS) like hydrogen peroxide, hydroxyl radica, and superoxide radical (Banerjee and Roychoudhury 2018d) (Fig. 2). The ROS non-specifically degrades proteins and nucleic acids and promotes lipid peroxidation. Membrane stability index is reduced leading to increased electrolyte leakage. Lipid-protein interactions and activities of membrane ATPases are severely hampered (Das and Roychoudhury 2014). In order to sequester ROS and detoxify their effects, plants increase the activities of antioxidative enzymes like superoxide dismutase (SOD), peroxidase (POX), catalase (CAT), etc. (Paul et al. 2017). High activities of SOD, POX and CAT have been observed in 
Raphanus sativus, Coriandrum sativum, Brassica juncea, and Spinacea oleracea exposed to F stress (Singh et al. 2013, Gadi et al. 2016). Mondal (2017) reported high CAT activity in indica rice irrigated with $\mathrm{F}$ contaminated water. The activities of CAT and glutathione peroxidase (GPX) prominently decrease with increased $\mathrm{F}$ stress in Zea mays, thus showing the $\mathrm{F}$ susceptibility of this genotype (Mutahir et al. 2016). The accumulation of non-enzymatic antioxidants like ascorbic acid (AsA) and phenolics has also been

\section{F accumulation in edible plant parts}

Bioaccumulation of $\mathrm{F}$ in the grains of staple crops like cereals and legumes and in the edible parts of vegetables is a direct threat to the entire food chain (Mondal and Gupta 2015). Popular edible plants like Cichorium spp., Brassica oleracea, Spinacea oleracea, Apium graveolens, etc., accumulate high amount of F (Hong et al. 2016). Such accumulation occurs after efficient root-to-shoot translocation from the soil or direct absorption from the atmosphere (Ambuvel et al. 2015). Gupta et al. (2009) reported an alarming accumulation of 5000 and 4000 $\mathrm{mg}(\mathrm{F}) \mathrm{kg}^{-1}$ (d.m.) in the indica rice seedlings irrigated with water contaminated by 20 and $30 \mathrm{mg} \mathrm{dm}^{-3} \mathrm{NaF}$, respectively, for $15 \mathrm{~d}$. The straw of such plants is unsuitable for animal feed and it is an indicator of high $\mathrm{F}$ accumulation also in the grains (Gupta et al. 2009).

\section{Phytoremediation}

Phytoremediation can be a cheap and environment friendly strategy for decontaminating $\mathrm{F}$ infested soils and waters via the use of green plants which have high translocation efficiency, bioconcentration factor, enrichment factor and tolerance to $\mathrm{F}$ (Lorestani et al. 2011). Such plants regarded as $F$ hyper-accumulators can be identified by screening trees, shrubs, and aquatic plants naturally thriving in the $\mathrm{F}$ infested areas. The selected species can accumulate appreciable amounts of $\mathrm{F}$ without manifesting phytotoxic effects and they maintain high biomass (Yoon et al. 2006).

Table 2 Suppl. represents the list of potential plant species capable of acting as $\mathrm{F}$ phytoremediators. The Prosopis juliflora belonging to Fabaceae is a popular choice for cleaning contaminated soils and groundwater. The tree has an extensive and deep root system and a very high root-to-shoot translocation (Saini et al. 2012). F tolerant plants have been screened among the vegetation thriving around phosphate fertilizer factories due to the positive correlation between phosphate and F content in the soil (Mezghani et al. 2005). Whereas F sensitive apricot leaves exhibited necrotic patches at $65 \mathrm{mg}(\mathrm{F}) \mathrm{kg}^{-1}$ (d.m.), olive trees could sustain up to $300 \mathrm{mg}(\mathrm{F}) \mathrm{kg}^{-1}$ (d.m.) without exhibiting any injurious symptom (Mezghani et al. 2005). In an interesting study, the arsenic contaminated groundwater contains also observed in several plant species after $F$ exposures (Table 1 Suppl.). The increase in the AsA content signifies higher efficiency of the AsA-glutathione cycle, the redox regulator in plant cells (Das and Roychoudhury 2014). Datta et al. (2012) reported higher activities of POX and AsA oxidase in Cicer arietinum plants grown under $\mathrm{F}$ stress in comparison to the controls. Studies covering the expression pattern of genes encoding antioxidants have not yet been reported.
Mondal (2017) demonstrated significant $F$ accumulation in indica rice cultivars with maximum translocation to shoots under exposure to $5 \mathrm{mg} \mathrm{dm}-3 \mathrm{NaF}$. Ambuvel et al. (2015) found the extent of $F$ accumulation to be higher than the WHO safe limit $\left(1.5 \mathrm{mg} \mathrm{kg}^{-1}\right)$ in indica rice and black gram seedlings irrigated with groundwater in Tamil Nadu, India. The leaves of Camellia sinensis accumulated $214 \mathrm{mg}(\mathrm{F}) \mathrm{kg}^{-1}$ (d.m.) when grown in $\mathrm{F}$ contaminated soils (Baunthiyal and Ranghar 2013).

Thus, it is advisable to prohibit the use of $\mathrm{F}$ contaminated water for irrigation purposes. However, in the present scenario, where large proportions of the soil, groundwater, and surface water are already affected with $\mathrm{F}$ contamination, new strategies for deconta-mination should be evolved. unusually high content of $F$ (Zhao et al. 2015). It was shown that 210 and $316 \mu \mathrm{M} F$ accelerate As (III) and As (V) uptake by Pteris vittata in hydroponic cultures (Zhao et al. 2015). Thus, $P$. vittata may be a suitable candidate for cleaning up the groundwater contaminated with both As and F. Boukhris et al. (2015) identified three perennials Rhanterium suaveolens, Atractylis serratuloides, and Erodium glaucophyllum, which are in situ phytoremediators on arid F polluted soils. Three semi-arid species, Acacia tortilis, Cassia fistula, and Prosopis juliflora were grown in 10, 20, and 50 $\mathrm{mg}(\mathrm{F}) \mathrm{kg}^{-1}$ (d.m.) in Soilrite for one month and no changes in Chl fluorescence parameters were observed (Baunthiyal and Sharma 2013). However, C. fistula plants exhibited $\mathrm{F}$ sensitivity in the later growth stages. The other species were F-tolerant.

Some aquatic algae and higher plants have evolved $F$ tolerance by increasing the endogenous $\mathrm{Ca}^{2+}$ content in order to sequester the free $\mathrm{F}$ ions (Table 2). Thus, $F$ remains inactivated as $\mathrm{CaF}_{2}$ in the roots and not translocated via the vascular tissues. Other deactivation mechanisms could be reprogramming of the cellular machinery and shift towards F-insensitive metabolic pathways (Santos-Diaz and Zamora-Pedraza 2010). Exhaustive metabolomic investigations are necessary to establish such possibilities. Karmakar et al. (2016) 
identified three aquatic macrophytes (Pistia stratiotes, Eichhornia crassipe,s and Spirodela polyrhiza) capable of removing F with an efficiency of 19.87, 12.71, and $19.23 \%$, respectively. Study of their physiological parameters like Chl and Car content, and CAT and POX activities showed that the plants were marginally affected during $\mathrm{F}$ stress and hence could be used as potential phytoremediators (Karmakar et al. 2016).

Intricate studies of characteristic F-induced injuries in sensitive plants can help in the environmental detection of F. These plants can be regarded as the 'bioindicators of

\section{Conclusion and future perspectives}

In spite of being one of the most abundant elements and representing about $0.3 \mathrm{~g} \mathrm{~kg}^{-1}$ of the earth's crust, the phytotoxic effects of $F$ have been insufficiently studied in plants. The elevated content of Fs are detected in silt clay loam soils and soil treated with phosphate fertilizers. The bioavailability of $\mathrm{F}$ depends on soil properties like $\mathrm{pH}$, sorption capacity, and permeability. Plants can be exposed to edaphic (soil) or atmospheric (in the form of HF) F stresses. Atmospheric F is absorbed mostly via the stomata. The uptake of soil Fs occurs via the roots and the absorbed $\mathrm{F}$ ions are then translocated to the stems, leaves, and storage organs via an apoplastic route. The exact localization of the accumulated $\mathrm{F}$ within the cell remains unclear. $\mathrm{F}$ phytotoxicity is primarily manifested by leaf tip burns, leaf scorch, and chlorosis. Excess $\mathrm{F}$ accumulation in sensitive plants inhibits vital processes like photosynthesis, $\mathrm{N}$ metabolism, signalling, nucleic acid synthesis, etc. and stimulate ROS production. Increased accumulation of ROS damages membranes and enzyme structures, but plants also accumulate nonenzymatic antioxidants like AsA and polyphenols and

\section{References}

Abdallah, F.B., Elloumi, N., Megfani, I., Garrec, J.P., Sfax, M.B., Tunisia, M.: Fluoride pollution of Jerbi grape leaves and the distribution of F, Ca, Mg and P in them. - Fluoride 39: 43-48, 2006.

Abugri, D.A., Pelig-Ba, K.B.: Assessment of fluoride content in tropical surface soils used for crop cultivation. - Afr. J. environ. Sci. Technol. 5: 653-660, 2010.

Agarwal, R., Chauhan, S.S.: Bioaccumulation of sodium fluoride toxicity in Triticum aestivum var. - Int. J. Food Agr. vet. Sci. 4: 98-101, 2014.

Ambuvel, D., Kumaresan, S., Jothibai, M.R.: F accumulation on paddy (Oryza sativa) and black gram (Phaseolus mungo Linn.) in cultivated areas of Kanyakumari district, Tamil Nadu, India. - Indian J. Fundam. Appl. Life Sci. 5: 280-285, 2015.

Anshumali, B.K.: Fluoride in agricultural soil: a review on its sources and toxicity to plants. - Global sustainability transitions: impacts - Innovations 3: 29-37, 2014.

Asada, M., Parkpian, P., Sumio, H.: Remediation technology for boron and fuoride contaminated sediments using green plants. - J. ASTM Int. 3: 304-310, 2005.
F pollution'. Rodriguez et al. (2012) monitored the $F$ induced visible effects on the leaves of Eucalyptus rostrata, Populus hybridus, and the needles of Pinus radiata trees growing around aluminium smelters. The tissues accumulated $6-3652 \mathrm{mg}(\mathrm{F}) \mathrm{kg}^{-1}$ (d.m.) with the maximum accumulation in $E$. rostrata. Washing of the leaves and needles removed the external $\mathrm{F}$, which reduced total $F$ content by 24,39 , and $51 \%$ in $E$. rostrata, $P$. hybridus, and $P$. radiata, respectively (Rodriguez et al. 2012).

increase the activity of enzymatic antioxidants like SOD, CAT, and POX to scavenge the toxic ROS. Expression profiles of genes encoding antioxidants should be studied in future.

The accumulation of $\mathrm{F}$ in edible plant parts is a serious threat to the animals and humans. In order to control such biohazards, F hyperaccumulators and tolerant species can be screened for possible phytoremediation. These species might contain very high content of antioxidants and efficient compartmentalization or effective export of $\mathrm{F}$ ions.

Phytoremediation is an easy and cost-effective approach to remove $\mathrm{F}$ from contaminated soils and water sources. However, the strategy is time consuming and sometimes partly efficient (Roy et al. 2015). In situations where the cultivated field is contaminated with $\mathrm{F}$, it would be economically challenging firstly clean the soil by planting $\mathrm{F}$ hyperaccumulators and after that cultivate crops or vegetables. Hence, it is important to genetically modify the crop plant to produce F-tolerant genotypes with low $\mathrm{F}$ bioaccumulation.
Banerjee, A., Roychoudhury, A.: Group II late embryogenesis abundant (LEA) proteins: structural and functional aspects in plant abiotic stress. - Plant Growth Regul. 79: 1-17, 2016.

Banerjee, A., Roychoudhury, A.: Abscisic-acid-dependent basic leucine zipper (bZIP) transcription factors in plant abiotic stress. - Protoplasma 254: 3-16, 2017.

Banerjee, A., Roychoudhury, A.: Strigolactones: multi-level regulation of biosynthesis and diverse responses in plant abiotic stresses. - Acta Physiol. Plant. 40: 86, $2018 \mathrm{a}$.

Banerjee, A., Roychoudhury, A.: The gymnastics of epigenomics in rice. - Plant Cell Rep. 37: 25-49, 2018 b.

Banerjee, A., Roychoudhury, A.: Effect of salinity stress on growth and physiology of medicinal plants. - In: Ghorbanpour, M., Varma A. (ed.): Medicinal Plants and Environmental Challenges. - Springer, Cham 2018c.

Banerjee, A., Roychoudhury, A.: Abiotic stress, generation of reactive oxygen species, and their consequences: an overview. - In: Singh, V.P., Singh, S., Tripathi, D., Mohan Prasad, S., Chauhan, D.K. (ed.): Revisiting the Role of Reactive Oxygen Species (ROS) in Plants: ROS Boon or Bane for Plants? Pp. 23-50. John Wiley \& Sons, Chichester 
2018d.

Barbier, O., Arreola-Mendoza, L., Del Razo, L.M.: Molecular mechanisms of $F$ toxicity. - Chem. Biol. Interact. 188: 319333, 2010.

Baunthiyal, M., Ranghar, S. Accumulation of $\mathrm{F}$ by plants: potential for phytoremediation. - Clean Soil Air Water 41: 16, 2013.

Baunthiyal, M., Sharma, V.: Phytoremediation of fluoride contaminated water and soil: a search for fluoride hyperaccumulators. - Int. J. Agr. Technol. 8: 1965-1978, 2012.

Baunthiyal, M., Sharma, V.: Response of three semi-arid plant species to fluoride: consequences for chlorophyll fluorescence. - Int. J. Phytoremediation 16: 397-414, 2013.

Bhargava, D., Bhardwaj, N.: Effect of sodium fluoride on seed germination and seedling growth of Triticum aestivum var. RAJ 4083. - J. Phytol. 2: 4-43, 2010.

Bhat, N., Jain, S., Asawa, K., Tak, M., Shinde, K., Singh, A., Gandhi, N., Gupta, V.V.: Assessment of fluoride concentration of soil and vegetables in vivinity of zinc smelter, Debari, Udaipur, Rajasthan. - J. Clin. Diagn. Res. 9: 63-66, 2015.

Boukhris, A., Laffont-Schwob, I., Mezghani, I., El Kadri, L., Prudent, P., Pricop, A., Tatoni, T., Chaieb, M.: Screening biological traits and fluoride contents of native vegetations in arid environments to select efficiently F-tolerant native plant species for in-situ phytoremediation. - Chemosphere 119: 217-223, 2015.

Cai, H., Dong, Y., Li, Y., Li, D., Peng, C., Zhang, Z., Wan, X.: Physiological and cellular responses to fluoride stress in tea (Camellia sinensis) leaves. - Acta Physiol. Plant. 38: 144, 2016.

Chakrabarti, S., Patra, P.K.: Biochemical and antioxidant responses of paddy (Oryza sativa L.) to fluoride stress. Fluoride 48: 56-61, 2015.

Chaves, A., Lucilvania, F.: The action of dissolved fluoride in artificial rain on leaf structure of Panicum maximum Jacq. (Colonião) and Chloris gayana Kunth. (Capim-Rhodes) Poaceae. - Acta bot. bras. 16: 395-406, 2002.

Chen, Y., Wang, S., Nan, Z., Ma, J., Zang, F., Li, Y., Zhang, Q.: Effect of fluoride and cadmium stress on the uptake and translocation of $\mathrm{F}$ and cadmium and other mineral nutrition elements in radish in single element or contaminated sierozem. - Environ. exp. Bot. 134: 54-61, 2017.

Choubisa, S.L.: Fluoride toxicosis in immature herbivorous domestic animals living in low $\mathrm{F}$ water endemic areas of Rajasthan, India: an observational survey. - Fluoride 46:1924, 2013.

Das, K., Roychoudhury, A.: Reactive oxygen species (ROS) and response of antioxidants as ROS-scavengers during environmental stress in plants. - Front. Environ. Sci. 2: 53, 2014.

Datta, J.K., Maitra, A., Mondal, N.K., Banerjee, A.: Studies on the impact of fluoride toxicity on germination and seedlings growth of gram seeds (Cicer arietinum L. cv. Anuradha). - J. Stress Physiol. Biochem. 8: 194-202, 2012.

Davison, A.W., Takmaz-Nisancioglu, S., Bailey, I.F.: The dynamics of fluoride accumulation by vegetation, in $\mathrm{F}$ toxicity. - In: Susheela, A.K. (ed.) Proceedings of the $13^{\text {th }}$ ISFR Conference. Pp. 30-46. ISFR, New Delhi 1985.

Elloumi, N., Abdallah, F.B., Mezghani, I., Rhouma, A., Boukhris, M.: Effect of fluoride on almond seedling in culture solution. - Fluoride 38: 193-198, 2005.

Farooqi, A., Masuda, H., Kusakabe, M., Naseem, M., Firdous, N.: A geochemical model for the abnormal fluoride concentrations in waters in parts of northern Tanzania. Geochem. J. 41: 213-234, 2007.

Gadi, B.R., Bhati, K., Goswami, B., Rankawat, R., Kumar, S.: Sources and phytotoxicity of fluorides in the environment. Environ. Impact. Biodivers. 2016: 251-266, 2016.

Gadi, B.R., Verma, P., Amra, R.: Influence of NaF on seed germination, membrane stability and some biochemicals content in Vigna seedlings. - J. chem. biol. phys. Sci. 2: 13711378, 2012.

Golicnik, M.: Metallic F complexes as phosphate analogues for structural and mechanistic studies of phosphoryl group transfer enzymes. - Acta chim. slov. 57: 272-287, 2010.

Gupta, S., Banerjee, S., Mondal, S.: Phytotoxicity of fluoride in the germination of paddy (Oryza sativa) and its effect on the physiology and biochemistry of germinated seedlings. - F 42: 142-146, 2009.

Hong, B.D., Joo, R.N., Lee, K.S., Lee, D.S., Rhie, J.H., Min, S.W., Song, S.G., Chung, D.Y.: Fluoride in soil and plant. Korean J. agr. Sci. 43: 522-536, 2016.

Iram, A., Khan, T.I.: Effect of sodium fluoride on seed germination, seedling growth and biochemistry of Abelmoschus esculentus. - J. Plant Biochem. Physiol. 4: 170, 2016.

Jha, S.K., Nayak, A.K., Sharma, Y.K.: Fluoride toxicity effects in onion (Allium cepa L.) grown in contaminated soils. Chemosphere 76: 353-356, 2009.

Kanduti, D., Sterbenk, P., Artnik, B.: Fluoride: a review of use and effects on health. - Mater. Sociomed. 28: 133-137, 2016.

Karmakar, S., Mukherjee, J., Mukherjee, S.: Removal of fluoride contamination in water by three aquatic plants. - Int. J. Phytoremediation 18: 222-227, 2016.

Kumar, A., Bhaskara, V.R.: Physiological responses to fluoride in two cultivars of mulberry. - World J. agr. Sci. 4: 463-466, 2018.

Lorestani, B., Cheraghi, M., Yousefi, N.: Phytoremediation potential of native plants growing on a heavy metals contaminated soil of copper mine in Iran. - World Acad. Sci. Eng. Technol. 77: 377-382, 2011.

Marier, R.: F Pollution. - http://Falert.org/ articles/growth-1975/, 1971.

Meenakshi,, Maheshwari, R.C.: Fluoride in drinking water and its removal. - J. Hazard. Mater. 137: 456-463, 2006.

Mezghani, I., Elloumi, N., Abdallah, F.B., Chaieb, M., Boukhris, M.: Fluoride accumulation by vegetation in the vicinity of a phosphate fertilizer plant in Tunisia. - Fluoride 38: 69-75, 2005.

Miller, G.W.: The effect of fluoride on higher plants with special emphasis on early physiological and biochemical disorders. F 26: 3-22, 1993.

Mondal, D., Gupta, S.: Influence of fluoride contaminated irrigation water on biochemical constituents of different crops and vegetables with an implication to human risk through diet. - J. Mater. Environ. Sci. 6: 3134-3142, 2015.

Mondal, N.K.: Effect of fluoride on photosynthesis, growth and accumulation of four widely cultivated rice (Oryza sativa L.) varieties in India. - Ecotoxicol. Environ. Safety 144: 36-44, 2017.

Mutahir, A., Bisht, M., Baunthiyal, M.: Comparative assessment of fluoride tolerance in two genotypes of Zea mays. - J. med. Plant Studies 4: 253-258, 2016.

Nanyaro, J.T., Aswathanarayana, Mungure, J.S.: A geochemical model for the abnormal fluoride concentrations in waters in parts of northern Tanzania. - J. Afr. Earth Sci. 2: 129-140, 1984.

Pal, C.K., Mondal, K.N., Bhaumik, R., Banerjee, A., Datta, K.J.: 
Incorporation of fluoride in vegetation and associated biochemical changes due to fluoride contamination in water and soil: a comparative field study. - Ann. Environ. Sci. 6: 123-139, 2012.

Panda, D.: Fluoride toxicity stress: physiological and biochemical consequences on plants. - Int. J. Bioresour. Environ. Agr. Sci. 1: 70-84, 2015.

Paul, S., Roychoudhury, A., Banerjee, A., Chaudhuri, N., Ghosh, P.: Seed pre-treatment with spermidine alleviates oxidative damages to different extent in the salt $(\mathrm{NaCl})$-stressed seedlings of three indica rice cultivars with contrasting level of salt tolerance. - Plant Gene 11: 112-123, 2017.

Pitman, M.G.: Fluoride transport across plant roots. - Rev. Biophys. 15: 481-554, 1985.

Pulyaevskaya, M.A., Varakina, N.N., Gamburg, K.Z., Rusaleva, T.M., Stepanov, A.V., Voinikov, V.K., Rikhvanov, E.G: Sodium fluoride inhibits HSP synthesis in heat-stressed cultured cells of Arabidopsis thaliana. - Russ. J. Plant Physiol. 58: 589-596, 2011.

Ram, A., Verma, P., Gadi, B.R.: Effect of fluoride and salicylic acid on seedlings growth and biochemical parameters of watermelon (Citrullus lanatus). - F 47: 49-55, 2014.

Rao, B.V.A., Kumar, A.K., Nagalaksmamma, K., Vidyunmala, S.: Effect of fluoride on protein profiles in two cultivars of mulberry leaves. - J. Agr. Environ. Sci. 13: 957-960, 2013.

Reddy, M.P., Kaur, M.: Sodium fluoride induced growth and metabolic changes in Salicornia brachiata Roxb. - Water Air Soil Pollut. 188: 171-179, 2008.

Rodriguez, J.H., Wannaz, E.D., Pignata, M.L., Fangmeier, A., Franzaring, J.: Fluoride biomonitoring around a large aluminium smelter using foliage from different tree species. Clean Soil Air Water 40: 1315-1319, 2012.

Roy, M., Giri, A.K., Dutta, S., Mukherjee, P.: Integrated phytobial remediation for sustainable management of arsenic in soil and water. - Environ. Int. 75: 180-198, 2015.

Roychoudhury, A., Banerjee, A.: Abscisic acid signaling and involvement of mitogen activated protein kinases and calcium-dependent protein kinases during plant abiotic stress. - In: Pandey, G. (ed.) Mechanism of Plant Hormone Signaling under Stress. Vol. 1. Pp. 197-241. John Wiley \& Sons, Hoboken 2017.

Roychoudhury, A., Banerjee, A., Lahiri, V.: Metabolic and molecular-genetic regulation of proline signalling and its cross-talk with major effectors mediates abiotic stress tolerance in plants. - Turk. J. Bot. 39: 887-910, 2015.

Saini, P., Baunthiyal, M., Sharma, V.: Organ-wise accumulation of $\mathrm{F}$ in Prosopis juliflora and its potential for phytoremediation of fluoride contaminated soil. Chemosphere 5: 633-635, 2012.

Saleem, M., Ahmad, N.M., Khan, A.B., Zia, A., Ahmad, S.S., Shah, U.H., Khan, A.N., Qazi, M.I.: Effects of soil fluoride on the growth and quality of two tomato varieties grown in Peshawar, Pakistan. - F 48: 174-178, 2015.

Santos-Díaz, M.S., Zamora-Pedraza, C.: Fluoride removal from water by plant species that are tolerant and highly tolerant to hydrogen fluoride. - Fluoride 43: 150-156, 2010.
Saxena, S., Rani, A.: Fluoride ion leaching kinetics for alkaline soils of Indian origin. - J. Sci. Res. Replicat. 1: 29-40, 2012.

Shirke, P.A., Chandra, P.: Fluoride uptake by duckweed Spirodela poyrrhiza. - Fluoride 24: 109-112, 1991.

Singh, M., Verma, K.K.: Influence of fluoride-contaminated irrigation water on physiological responses of poplar seedlings (Populus deltoides L. clone-S7C15). - F 46: 83-89, 2013.

Singh, M., Verma, K.K., Verma, C.L.: An approach to develop a model for describing the influence of fluoride-contaminated irrigation water on physiological responses in poplar (Populus deltoides clone S7C15). - Acta Physiol. Plant. 35: 3357-3364, 2013.

Sinha, S., Saxena, R., Singh, S.: Fluoride removal from water by Hydrilla verticillata (1.f.) Royle and its toxic effects. - Bull. Environ. Contam. Toxicol. 65: 683-690, 2000.

Stevens, D., McLaughlin, M.J., Alston, A.M.: Phytotoxicity of the fluoride ion and its uptake from solution culture by Avena sativa and Lycopersicon esculentum. - Plant Soil 200: 119129, 1998.

Struglics, A., Fredlund, K.M., Konstantinov, Y.M., Allen, J.F., Müller, I.M.: Protein phosphorylation/ dephosphorylation in the inner membrane of potato tuber mitochondria. - FEBS Lett. 475: 213-217, 2000.

Susheela, A.K.: Fluorosis management programme in India. Curr. Sci. 77: 10, 1999.

Szostek, R., Ciecko, Z.: Effect of soil contamination with fluoride on the yield and content of nitrogen forms in the biomass of crops. - Environ. Sci. Pollut. Res. 24: 8588-8601, 2017.

Tylenda, C.A.: Toxicological Profile for Fluorides, Hydrogen Fluoride and Fluorine. - DIANE Publishing, Darby 2011.

Vasudevan, D., Harrington, L.F., Cooper, E.M.: Fluoride sorption and associated aluminum release in variable charge soils. - J. Colloid. Interface Sci. 267: 302-313, 2003.

Wallis, W.J., Miller, G.W., Psenak, M., Shieh, J.: Fluoride effects on chlorophyll biosynthesis in Nicotiana tabacum. - Fluoride 7: 69-77, 1974.

Walna, B., Kurzyca, I., Bednorz, E., Kolendowicz, L.: Fluoride pollution of atmospheric precipitation and its relationship with air circulation and weather patterns (Wielkopolski National Park, Poland). - Environ. Monit. Assess. 185: 54975514, 2013.

Wang-Cahill, F.: Investigation of fluoride distribution in deciduous trees at a hazardous waste landfill. - In: The Annual International Conference on Soils, Sediments and Water. University of Massachusetts, Amherst 2007.

Wehr, J.B., Kopittke, P.M., Scholz, L., Menzies, N.W.: Understanding the Movement of Fluoride from Soils into the Broader Ecosystem. - The University of Queensland, School of Agriculture and Food Sciences, Gatton 2014.

Yoon, J., Cao, X., Zhou, Q., Ma, L.Q.: Accumulation of Pb, Cu, and $\mathrm{Zn}$ in native plants growing on a contaminated Florida site. - Sci. Total Environ. 368: 456-464, 2006.

Zhao, J., Guo, H., Ma, J., Shen, Z.: Effect of fluoride on arsenic uptake from arsenic-contaminated groundwater after using Pteris vittata L. - Int. J. Phytoremediation 17: 355-362, 2015. 